\title{
Identification of Medical Errors Reporting Barriers from the Viewpoints of Operating Room Technologists in Educational and Therapeutic Centers Affiliated to Iran University of Medical Sciences
}

\author{
Hannani. $S^{1}$ \\ Khachian. $A^{2}$ \\ Haghani. $\mathrm{H}^{3}$ \\ ${ }^{*}$ Rahmani. V4 \\ 1-MSc in Nursing, Operating \\ Room Department, Faculty of \\ Allied Medical Sciences, Iran \\ University of Medical Sciences, \\ Tehran, Iran. \\ 2- Ph.D., in Nursing Education, \\ Medical Surgical Nursing \\ Department, Faculty of Nursing \\ and Midwifery, Iran University of \\ Medical Sciences, Tehran, Iran \\ 3- Ph.D., in Biostatistics, Faculty of \\ Management, Iran University of \\ Medical Sciences, Tehran, Iran. \\ 4- ( ${ }^{*}$ Corresponding Author) \\ MSc Student of Operating \\ Room, Faculty of Allied Medical \\ Sciences, Iran University of \\ Medical Sciences, Tehran, Iran. \\ Email:Rahmani.v@tak.iums.ac.ir
}

\begin{abstract}
Introduction: The operating room can be used to treat various types of medical errors due to numerous invasive procedures. The effects of recording error messages and timely reporting on preventing it and improving patient safety are of great importance.
\end{abstract}

Objective: The present study aimed to determine the barriers of medical reporting errors from the viewpoints of operating room technologists of the educational and therapeutic centers affiliated to Iran University of Medical Sciences in 2019.

Material and Methods: The present study was a descriptive-analytical and temporal cross-sectional study performed on 152 operating room technologists selected using convenience sampling in 2019. The tool included demographic information and medical reporting errors. Data were analyzed using SPSS 22.

Results: The Mean and standard deviation of total error reporting barriers was $1.98 \pm 0.36$ (out of 3 ). The mean score of error reporting barriers in the four areas under review shows that the highest and lowest error reporting barriers results from legal domain (2.14 \pm 0.49$)$ and financial factor (1.85 \pm 0.51$)$, respectively The highesterror reporting barriers were subject to "personal accusation", "fear of accusations and being charged of" and "Workload". The results of the t-test and analysis of variance showed that there was a significant difference between the error reporting barriers, gender $(\mathrm{P}=0.026)$ and work experience $(\mathrm{P}=0.031)$. However, there was no significant correlation between error reporting barriers and other variables $(\mathrm{P}>0.05)$.

Discussion and Conclusion: Exposing the person to accusations and fearing the consequences of reporting was one of the most important obstacles in delivering reporting errors. In this regard, the most important step in removing this obstacle is to create a space in which each room technologist expresses errors honestly and without fear and the reason for its occurrence to the other treatment team. Therefore, it is recommended that proper interaction be established between the operating room technologists and the authorities.

Keywords: Error, Medical Errors, Operating Room Staff, Reporting Barriers. 


\title{
شناسايى موانع تزارشدهى خطاهاى يزشكى از ديدكاه تكنولوزيستهاى اتاق عمل مراكز

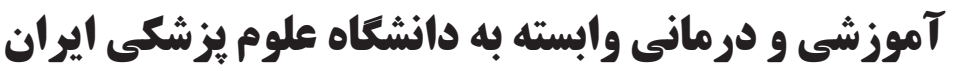

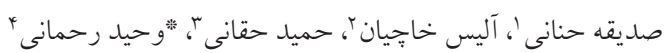

جكيده

مقدمه: اتاق عمل با توجه به انجام يروسيجرهاى تهاجمى مختلف مى تواند بسترى براى وقوع انواع خطاهاى يزشكى باشد.

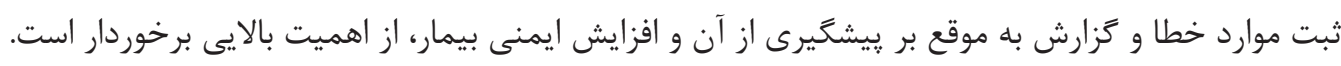

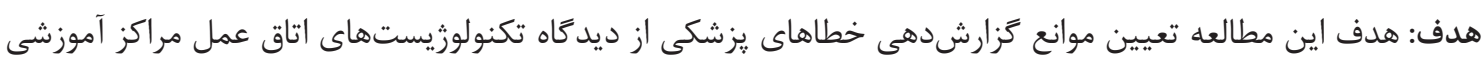

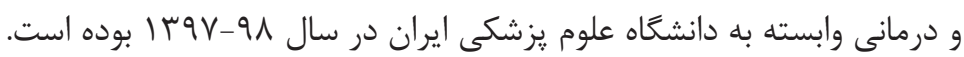

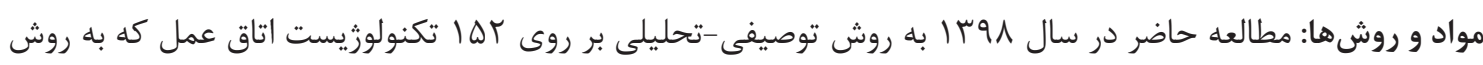

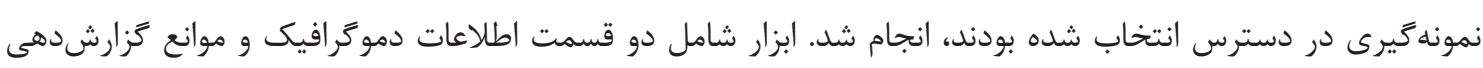

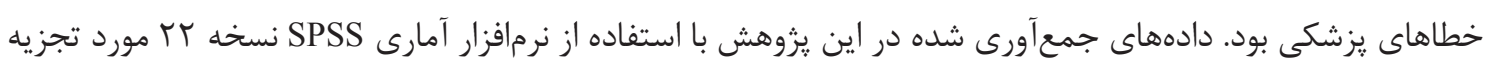
و تحليل قرار ترفت.

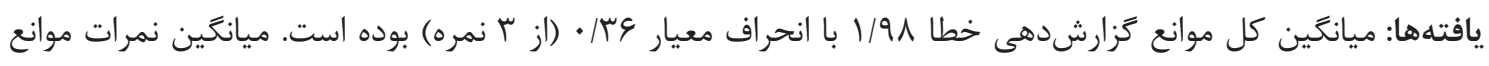

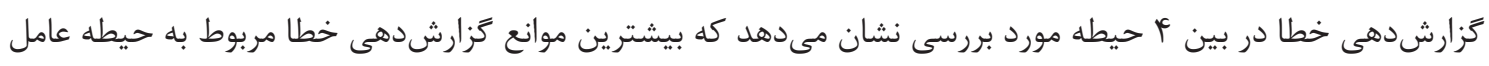

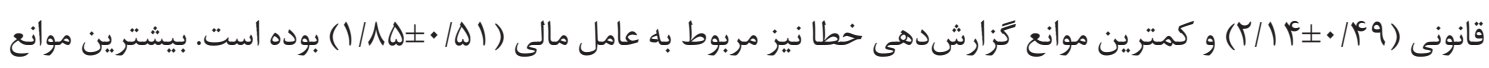

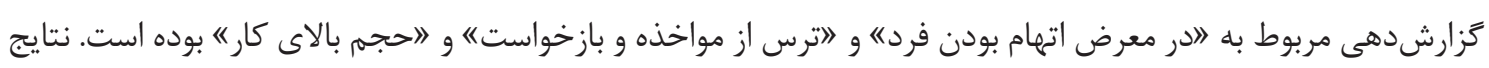

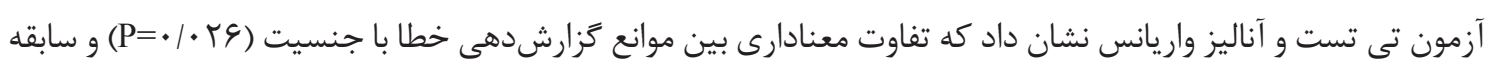

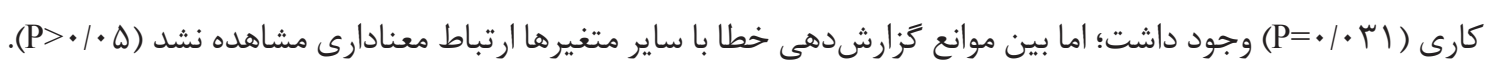

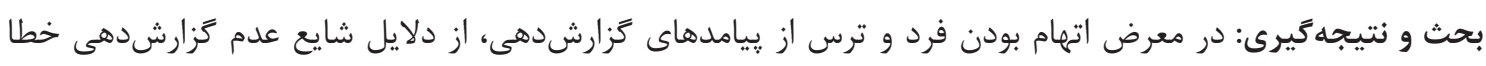

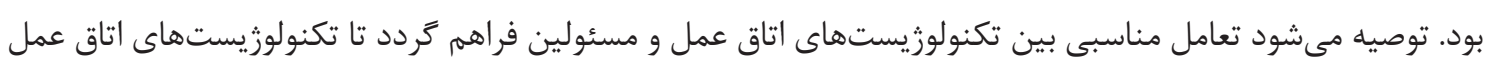

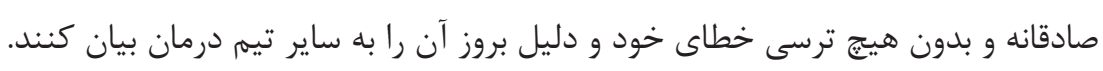

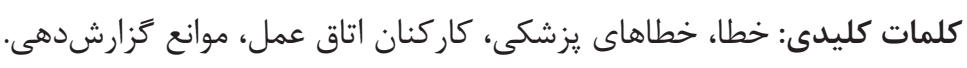

تاريخ دريافت:

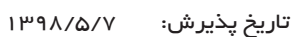

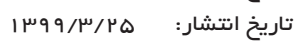

بهداشتى تهديد مى كنند (1). به همين دليل، پيشگيرى از مقدمه

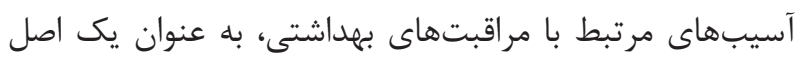

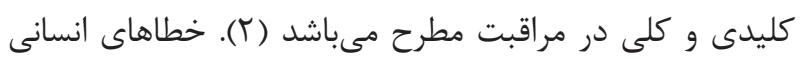

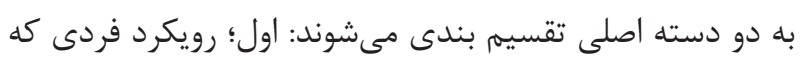
دانش يزشكى بر اساس اصل "اول، بدون هيج آسيبى" بنا نهاده

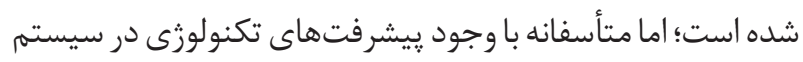

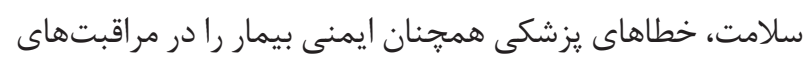


نيازمند وجود كزارش دهى به طور رسمى در سازمان است، در غير

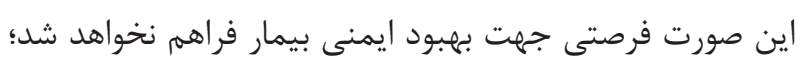

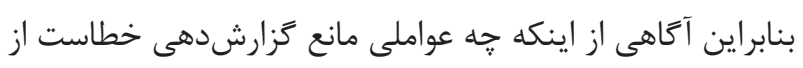

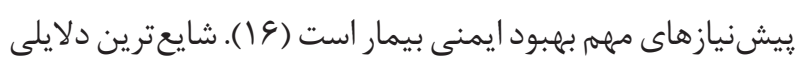
كه منجر به عدم گزارشدهى خطا مىشود، شامل نغرانى ارائه دهند ان مراقبتهاى سلامت در مورد اقدامات انضباطى و برخورد

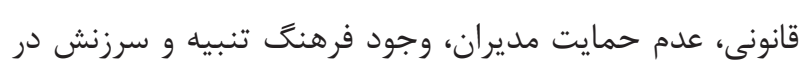

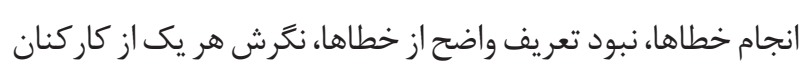
در مورد كزارشدهى خطا و موضوعات حريم خصوصى بيماران

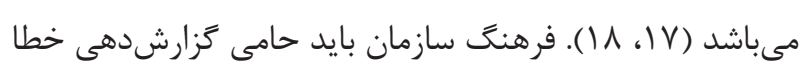
باشد و از سرزنش افرادى كه خطايى مرتكب مى شوند يرهيز كند، زمانى كه تزارشدهى تشويق و خطاها بررسى مى شود، اين كار

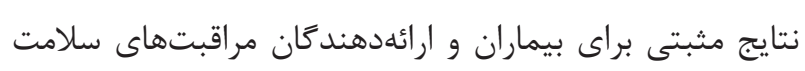
دارد (19). در كشورهاى در حال توسعه، به دليل عدم وجود سيستم ثبت

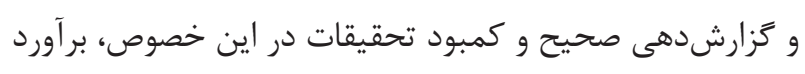

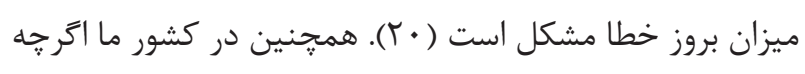

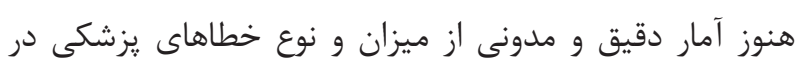

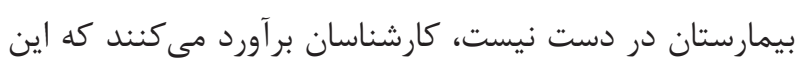
ميزان بسيار بالا باشد و افزايش يروندههاى شكايات مردم از دئن

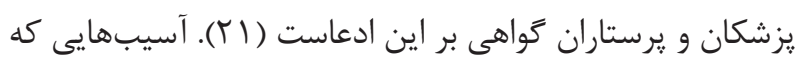

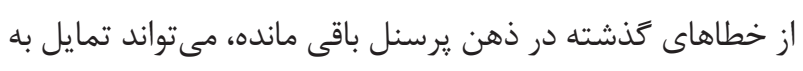

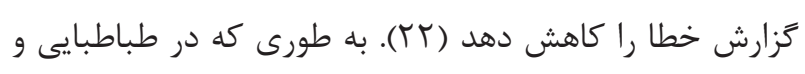

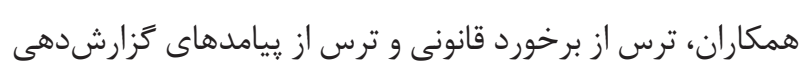

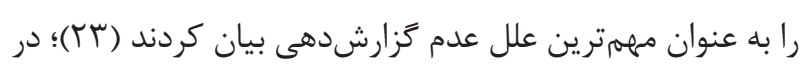

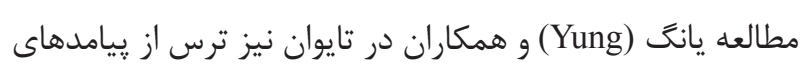
كزارش دهى را به عنوان مهمترين موانع كزارش دهنى اعلام نمودند

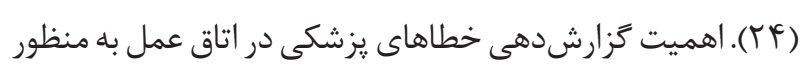

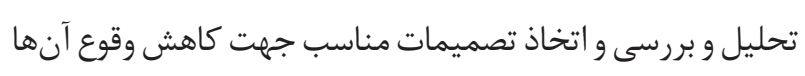

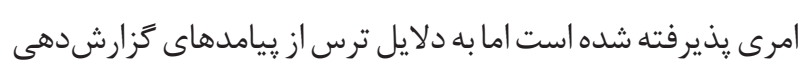

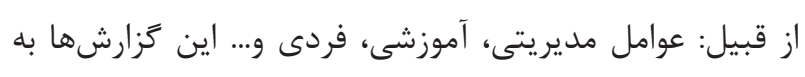

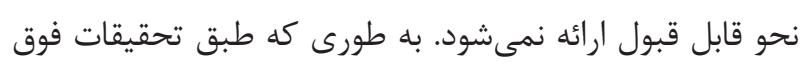

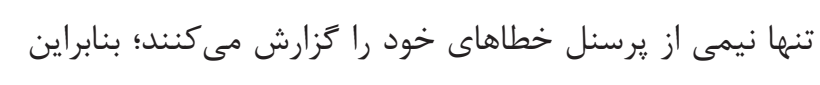

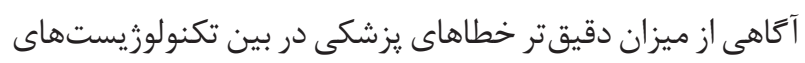

تمر كز بر اشتباهاتى دارد كه در نتيجه عوامل روانشناختى از قبيل

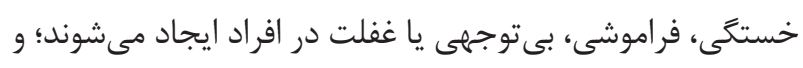

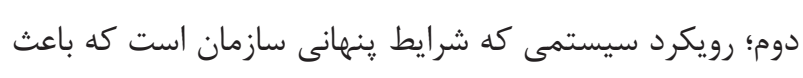

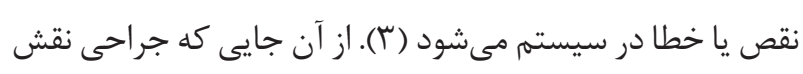

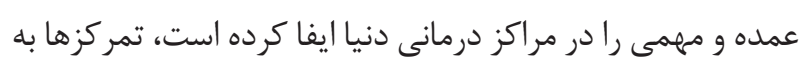

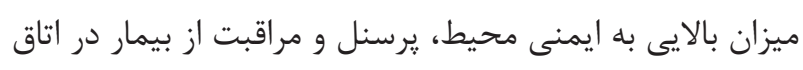

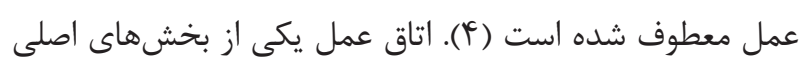

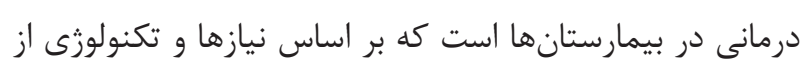

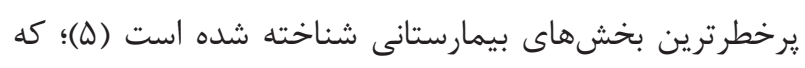

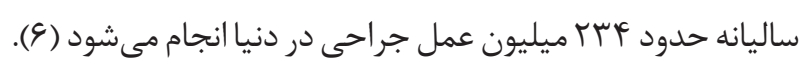

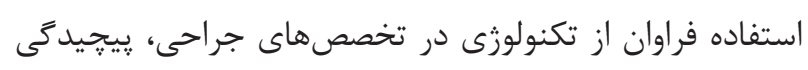

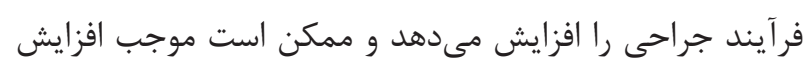

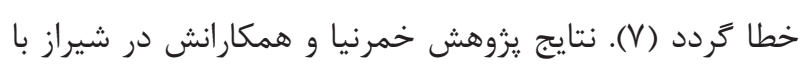
عنوان بررسى خطاهاى يزشكى در بيمارستان هاى دولتى نشان داد

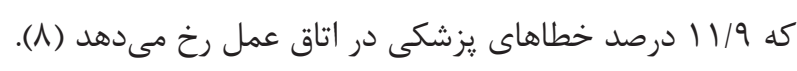
كام اساسى و مههم براى كاهش خطا، تشخيص علل و زمينه

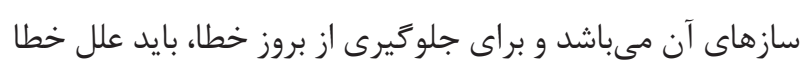

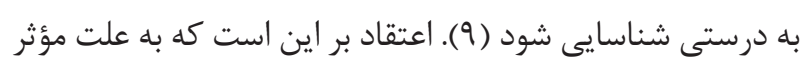
نبودن سيسته كزارش دهى خطا و برخى ضعف هاى ساختارى در

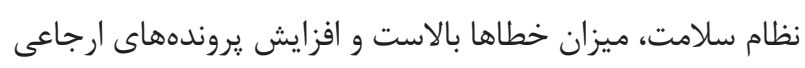
شكايت مردم از مراكز درمانى، دليل بر اين باور است (• ().

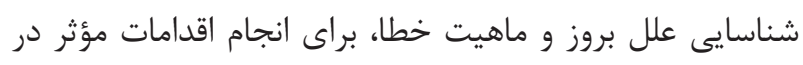

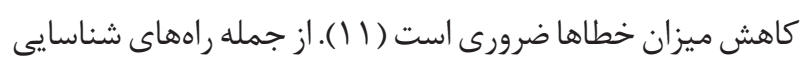

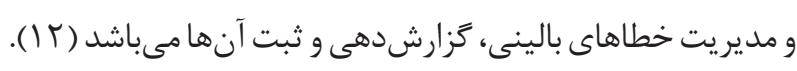

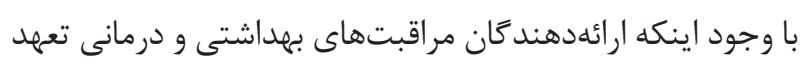
اخلاقى و حرفهاى به كزارش خطاهاى كارى خود دارند اما ميزان كزارش خطا در بين يرستاران بسيار كمتر از ميزان واقعى آن

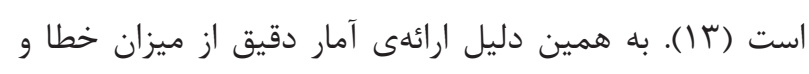

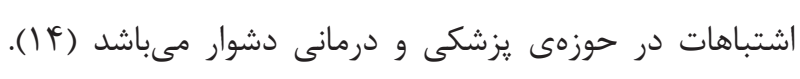

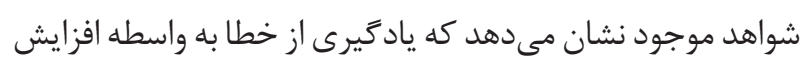

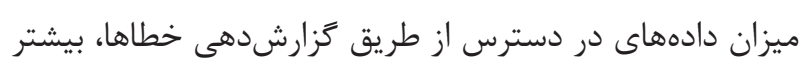

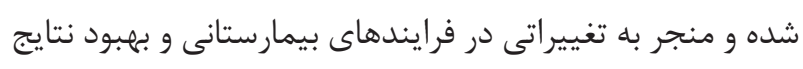

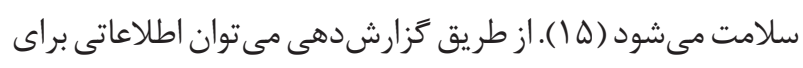

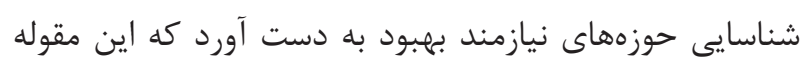


نمرهذذارى سؤالات بر اساس اهميت عامل و به صورت ليكرت سه ززينهاى (كم، متوسط، ضعيف) بود. در حيطه عامل قانونى ستى

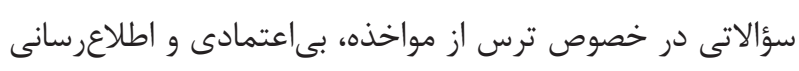

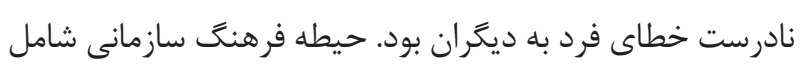

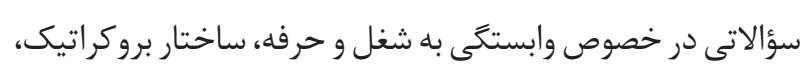

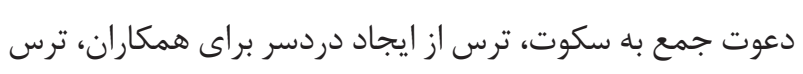

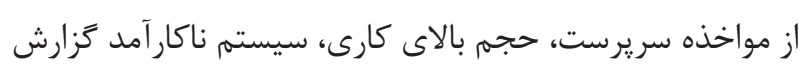

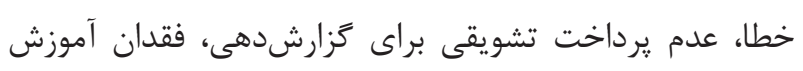

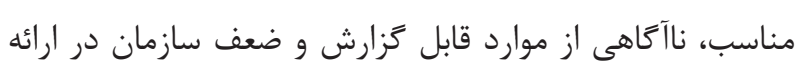

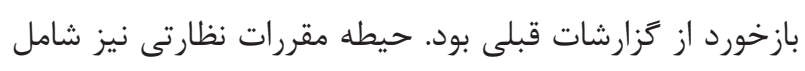
سؤالاتى در خصوص در معرض اتهام بودن فرد، افزايش تعرفه

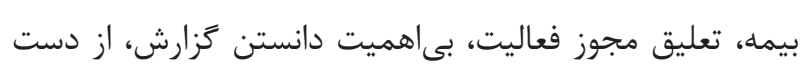

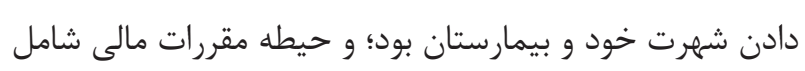

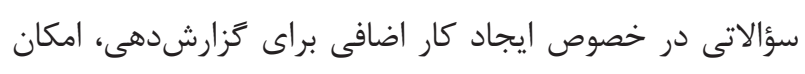

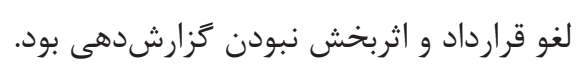

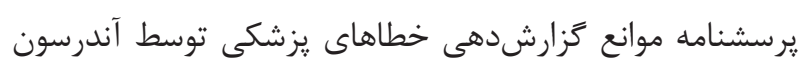
و همكارانش در سال 9 . . T طراحى شده (rDderson)

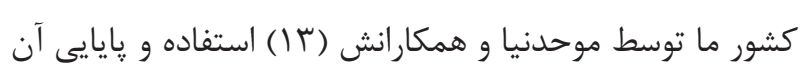
با ضريب آلفاى كرونباخ هA| • تزارش شده است. براى اطمينان

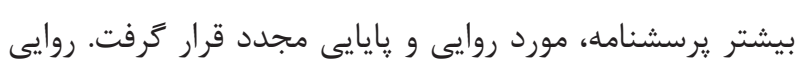

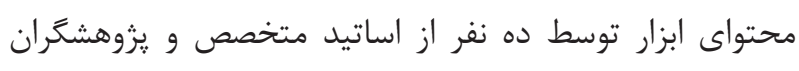

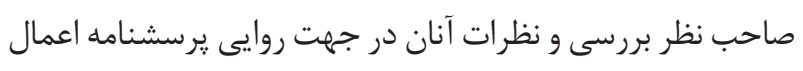
كرديد؛ و بايايى آن توسط روش آزمون مجدد اعتبارسنجى شد شد.

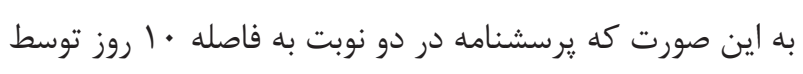

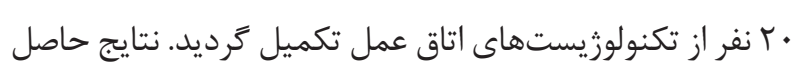

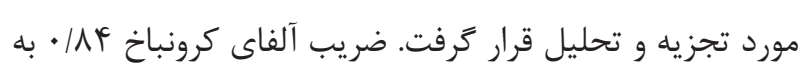
دست آمد. در نهايت يس از جمع آورى دادهها، به منظور بررسى نرمال بودن

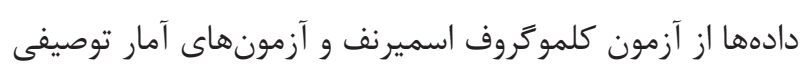

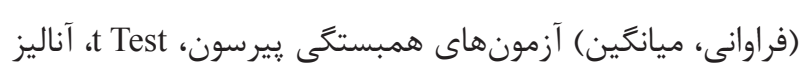

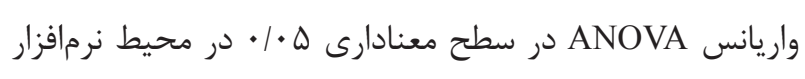
نسخه TrSS اين يزوهش در كميته اخلاق در يزوهش دانشعاه علوم يزشكى ايران

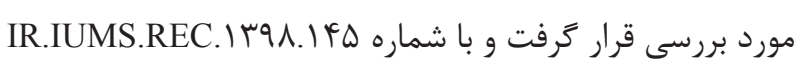

اتاق عمل مى توانند در اتخاذ تصميمات كلان مديريتى و همجنين برَزارى دورههاى آموزشى و رفع نواقص، مفيد واقع شود.

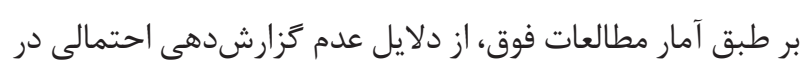

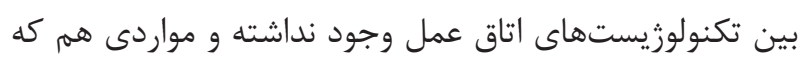

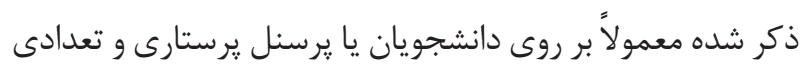

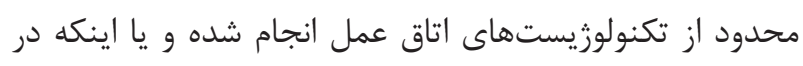

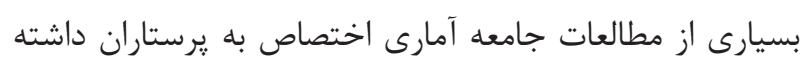

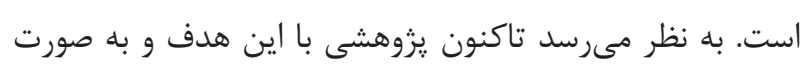
اختصاصى بر روى تكنولوزيستهاى اتاق عمل انجام نشده است.

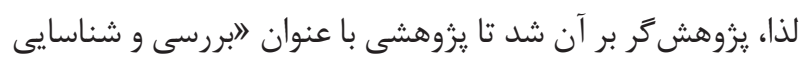

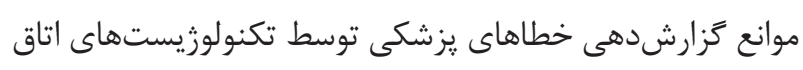

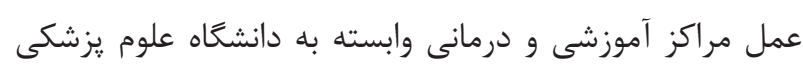

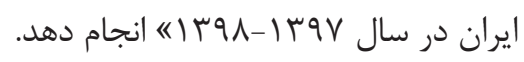

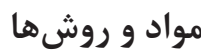

اين يزوهش يك مطالعه توصيفى تحليلى از نوع مقطعى است.

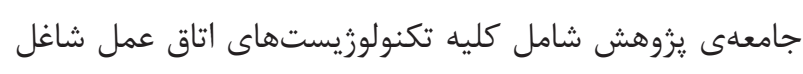

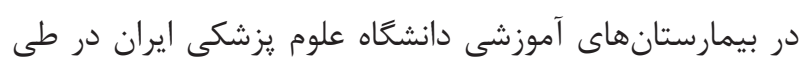

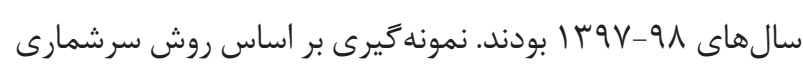
بود و در مجموع U ال نفر از تكنولوزيستهاى اتاق عمل مراكز

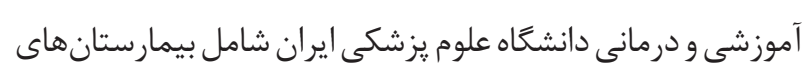

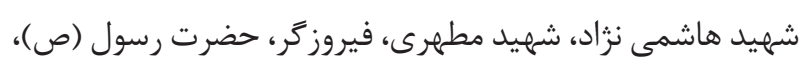

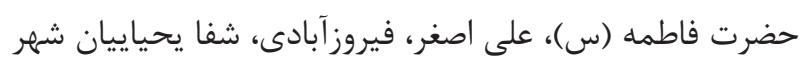

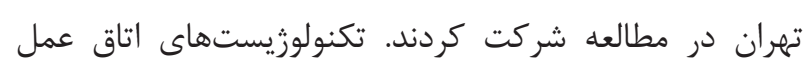
شاغل در بيمارستانهاى مذكور داراى مدرك كاردانى يا بالاتر در رشتهاى اتاق عمل و يرستارى بودند و حداقل 9 ماه سابقه كار

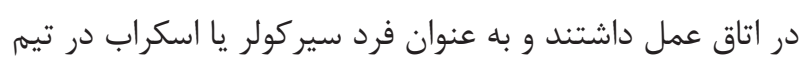
جراحى فعاليت داشتند. ابزار گردآورى اطلاعات شامل دو بخش بوداليت داشتئ بخش اول، يرسشنامه

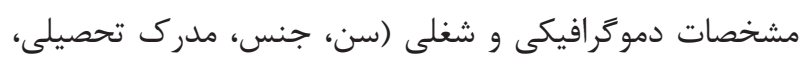

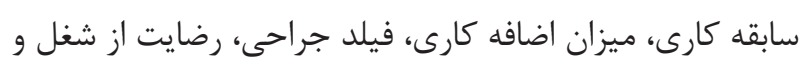

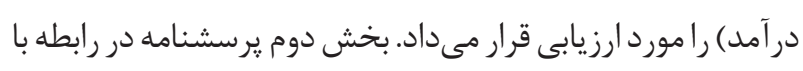

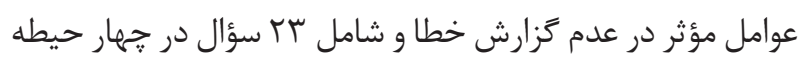
(عامل قانونى، عامل فرهنَ سازمانى، مقررات نظارتى و مالى) بود. 
عمل

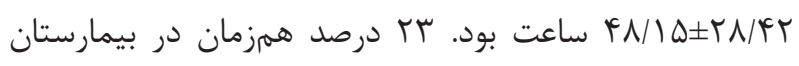

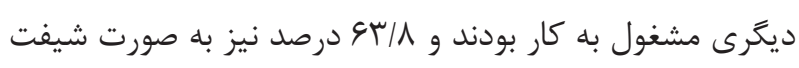

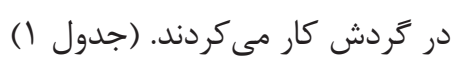

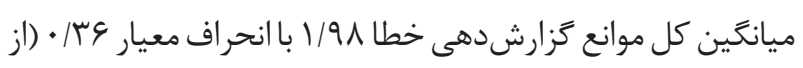

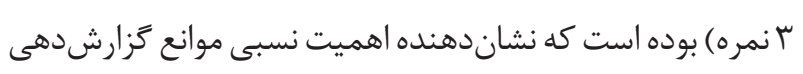

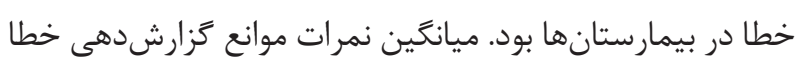

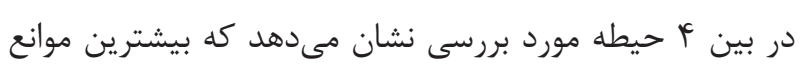

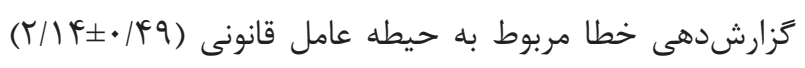
و كمترين موانع كزارشدهى خطا نيز مربوط به عربه عامل مالى

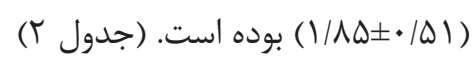

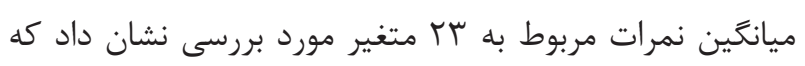

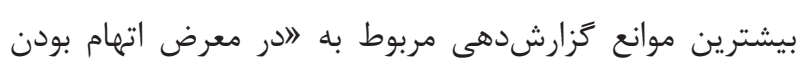

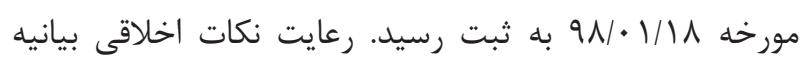
هلسينكى، اخذ رضايت آكاهانه از تكنولوزيستهاى اتاق عمل،

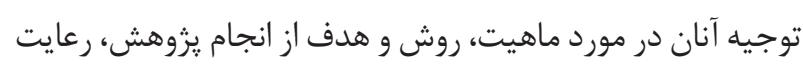

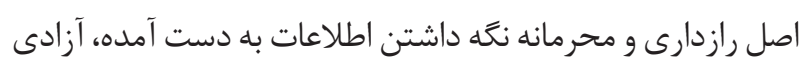

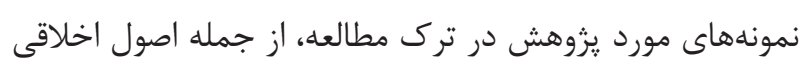
بودند كه در اين يزوهش رعايت شدند.

يافتهها

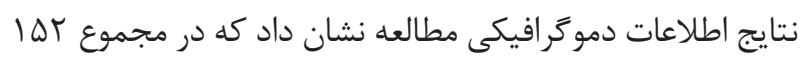
نفر از تكنولوزيستهاى اتاق عمل با ميانگين سنى

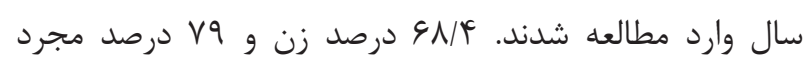
بودند. همجنين

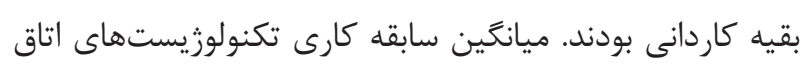

جدول ا- ارتباط بين مشخصات دموكر افيكى و موانع تزارش دهى خطاهاى بزشكى

\begin{tabular}{|c|c|c|c|}
\hline 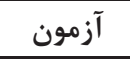 & فراوانى (درصد) & & متغير \\
\hline \multirow{4}{*}{$\mathrm{P}=\cdot / \pi \kappa}$. & $(I F / D) T r$ & كمتر از ها & \multirow{4}{*}{ سن } \\
\hline & (rG/T) DQ & $r \cdot-r \Delta$ & \\
\hline & سץ (Y)/V) & 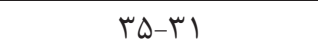 & \\
\hline & $(T V / G) F T$ & بالاتر از هـ & \\
\hline \multirow{2}{*}{$\mathrm{P}=\cdot / \cdot r \varphi$} & $(\Psi / 9) \& \wedge$ & 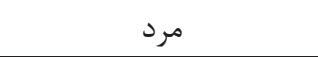 & \multirow{2}{*}{ جنسيت } \\
\hline & $(\varepsilon \wedge / F) 1 \cdot \mathcal{F}$ & 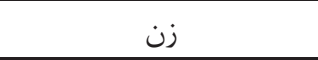 & \\
\hline \multirow{2}{*}{$\mathrm{P}=\cdot|\mathrm{V} \varepsilon|$} & $(\Delta Y) \vee q$ & 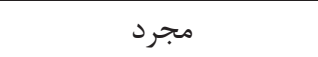 & \multirow{2}{*}{ 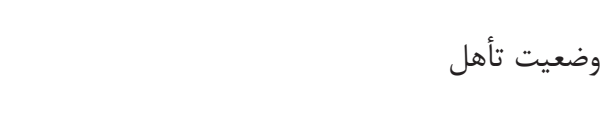 } \\
\hline & $(\uparrow \wedge) \vee r$ & متأهل & \\
\hline \multirow{2}{*}{$\mathrm{P}=\cdot \mid \Lambda \Delta \Lambda$} & $(\mid q / F) r \Delta$ & كاردانى & \multirow{2}{*}{ تحصيلات } \\
\hline & $(\Lambda T / 9) I T V$ & كارشناسى & \\
\hline \multirow{3}{*}{$\mathrm{P}=\cdot \mid \cdot \mu_{1}$} & $(\Gamma \cdot / \mu) \notin \varepsilon$ & كمتر از ه سال & \multirow{3}{*}{ سابقه كارى } \\
\hline & $(r \Lambda / r) F r$ & $1 \cdot-\theta$ & \\
\hline & $(\boldsymbol{f} / / \mathbb{f}) \&$ & بيشتر از • ا سال & \\
\hline \multirow{2}{*}{$\mathrm{P}=\cdot / T r \Lambda$} & $(\Phi+/ \Delta) 91$ & كمتر از • له ساعت در ماه & \multirow{2}{*}{ ميزان اضافه كارى } \\
\hline & $(r \Delta / \Delta) \Delta F$ & بيشتر از ·له ساعت در ماه & \\
\hline \multirow{2}{*}{$\mathrm{P}=\cdot / T r \Delta$} & D & بلى & \multirow{2}{*}{ اشتغال همزمان در بيمارستان ديخر } \\
\hline & $(V V) \backslash 1 V$ & خير & \\
\hline \multirow{4}{*}{ 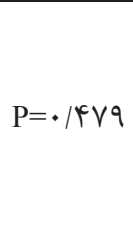 } & $(\mid \Lambda / F) r \Lambda$ & صبح & \multirow{4}{*}{ شيفت كارى غالب } \\
\hline & سז (1ه/I) & ع عصر & \\
\hline & $(Y / q) Y$ & شب & \\
\hline & $(9 \mu / \Lambda) 9 \vee$ & در گردش & \\
\hline
\end{tabular}


جدول r- نمرات حيطهها و كويهها به تفكيك (N=IVT)

\begin{tabular}{|c|c|c|c|}
\hline ميانغين و انحراف معيار & ميانَين و انحراف معيار & تويه & حيطه \\
\hline \multirow{3}{*}{ 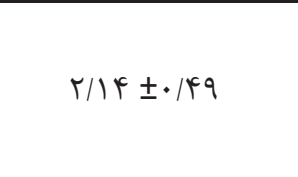 } & $r / r F \pm \cdot 19 q$ & ترس از مواخذه و بازخواست & \multirow{3}{*}{ 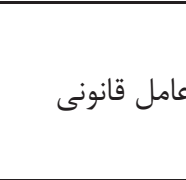 } \\
\hline & $T / \cdot I \pm \cdot / V \Delta$ & بى اعتمادى & \\
\hline & $Y / \cdot V \pm \cdot / V Y$ & اطلاعرسانى نامناسب خطاى فرد به ديخران & \\
\hline \multirow{11}{*}{$r / \cdots \pm \cdot / \mu}$. & I/VA $\pm \cdot / \vee G$ & وابستخى شديد به حرفه و شغل & \multirow{11}{*}{ سازمل فرهنَ } \\
\hline & $1 / \wedge \Delta \pm \cdot / 9 \Lambda$ & ساختار بروكراتيك & \\
\hline & I/VA $\pm \cdot / V 9$ & دعوت جمع به سكوت & \\
\hline & $1 / 9 r \pm \cdot / V \wedge$ & ترس از ايجاد دردسر براى همكاران & \\
\hline & $r / 19 \pm \cdot / V V$ & ترس از مواخذه سريرست مستقيم & \\
\hline & $r / r q \pm \cdot / V q$ & حجم بالاى كار & \\
\hline & $T / / r \pm \cdot / V V$ & سيستم ناكارآمد كَارش خطا & \\
\hline & $1 / \wedge \cdot \pm \cdot / \wedge \Delta$ & عدم يرداخت تشويقى براى كزارش خطا & \\
\hline & $r / I r \pm \cdot / V \Delta$ & فقدان آموزش در زمينه خطاهاى شايع هر فرآيند يا يروسيجر & \\
\hline & $1 / 99 \pm \cdot / \mathrm{VI}$ & نآكاهى از مواردى كه بايد كزارش شود & \\
\hline & $r / l \cdot \pm \cdot / V q$ & ضعف سازمان در ارائه بازخورد در مورد كزارشات قبلى & \\
\hline \multirow{4}{*}{$1 / 90 \pm \cdot / 4 q$} & $r / r \Lambda \pm \cdot / V r$ & در معرض اتهام بودن فرد & \multirow{4}{*}{ 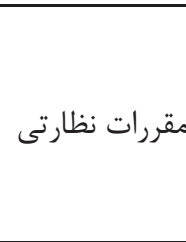 } \\
\hline & $1 / 9 \cdot \pm \cdot / V \Delta$ & افزايش تعرفه بيمه مسئوليت براى فرد & \\
\hline & $1 / Y Y^{E} \pm \cdot / \Lambda$ & تعليق مجوز فعاليت و كار & \\
\hline & $r / \cdot 9 \pm \cdot / 1 \cdot$ & بىاهميت و بىفايده دانستن كزارش خطا & \\
\hline \multirow{5}{*}{$1 / \Lambda \Delta \pm \cdot|\Delta|$} & $r / r T \pm \cdot / V \Delta$ & از دست دادن شهرت و يا شغل & \multirow{5}{*}{ 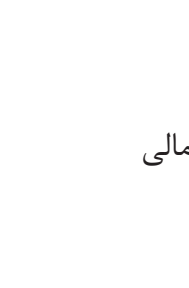 } \\
\hline & $1 / 9 V \pm \cdot / V V$ & از دست رفتن شهرت بيمارستان & \\
\hline & $1 / \Lambda \cdot \pm \cdot / V V$ & ايجاد كار اضافى براى فرد & \\
\hline & $1 / \Lambda \Lambda \pm \cdot / \Lambda$ & امكان لغو قرارداد & \\
\hline & $1 / 9 V \pm \cdot / V \Delta$ & هزينه -اثربخش نبودن گززارشدهى & \\
\hline
\end{tabular}

\section{بحث و نتيجه}

بر اساس نتايج مطالعه حاضر، ميانگين كل نمره موانع گزارشدهى خطا در بين تكنولوزيستهاى اتاق عمل 1/91 از ب بود كه به طور كلى در سطح متوسطى قرار داشت. ميانخين نمره موانع Fزارشدهى خطا در مطالعه ابوشيكا (Aboshaiqah) نيز از ه بود كه در سطح متوسطى قرار داشت (צ؟). دانشكهن و همكاران نيز در كشورمان بيان كردند كه ميانگين نمره موانع ززارشدهى خطا در سطح متوسط قرار دارد كه به نتايج مطالعه حاضر بسيار نزديك است (YV) شناسايى موانع و تسهيل كنندههاى گزارش دهى خطا در طراحى و
فرد" و "ترس از مواخذه و بازخواسته و "حجم بالاى كار" بوده است و كمترين موانع زَزارشدهى مربوط به \افزايش تعرفه بيمه مسئوليت براى فرد" و 》 از دست رفتن شهرت بيمارستان "و "هزينه-اثربخش نبودن ززارشدهى" بوده است. يافتههاى حاصل از نتايج آزمون كولموگروف - اسميرنف نشان داد كه متغيرهاى موانع گزارشدهى خطا از توزيع نرمال ييروى مى كند. نتايج آزمون تى تست و آناليز واريانس نشان داد كه تفاوت

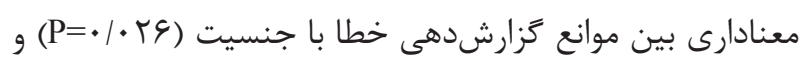

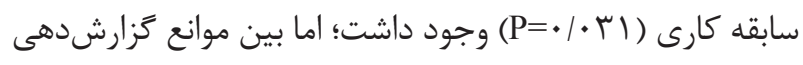
خطا با ساير متغيرها ارتباط معنادارى مشاهده نشد. 
جايغزين آن شود (rᄉ) كميته استراليايى ايمنى و كيفيت مراقبت سلامت The Australian Commission on Safety and Quality in Health Care: ACSQHC)

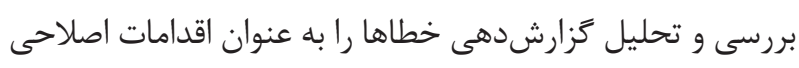
در جهت ارتقا ايمنى بيمار و كيفيت مراقبتها بيان كرد (• (ب).

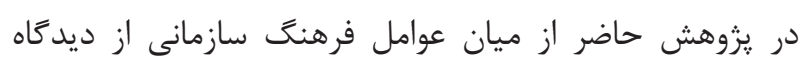

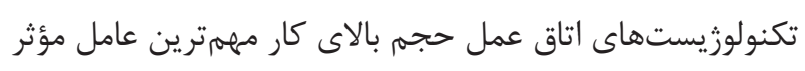

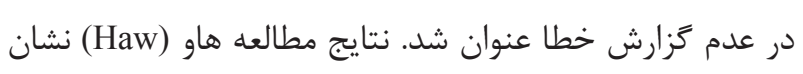

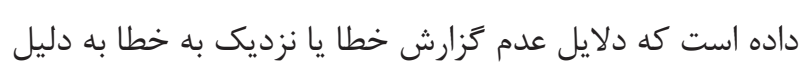

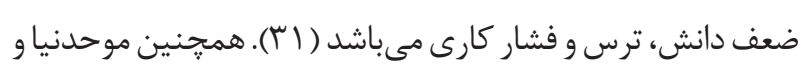

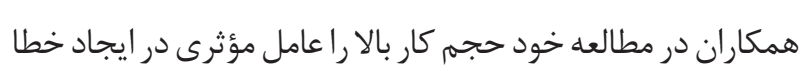

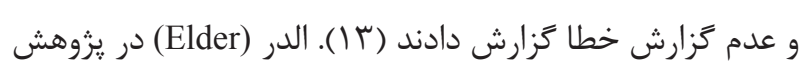

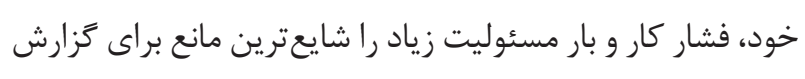

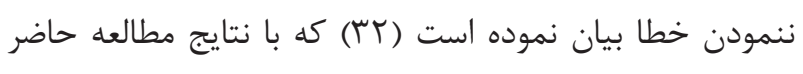
همخوانى دارد. به نظر مىرسد اين موضوع به دليل عدم رعايت ندوده

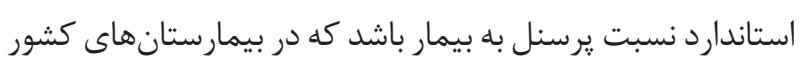

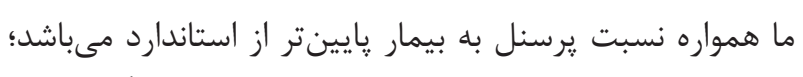

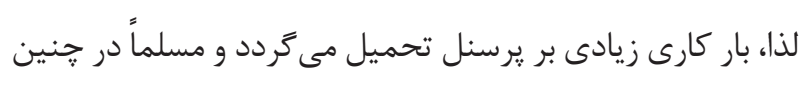
شرايطى كارايى و دقت يرسنل افت بِيدا مى كند.

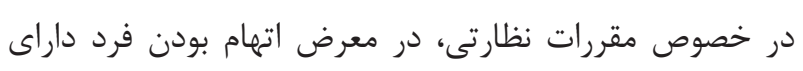

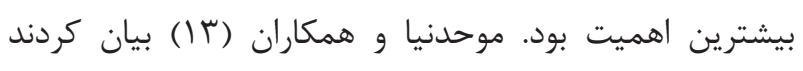

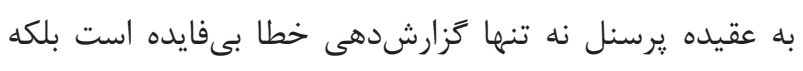

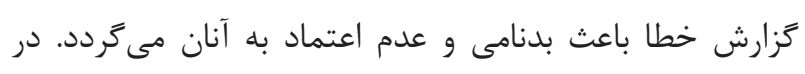

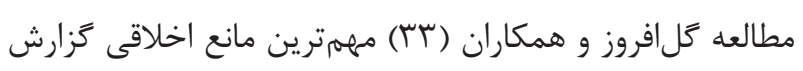
خطا، عدم حمايت يزشك از برستارِ مرتكب اشتباه بود، احساس

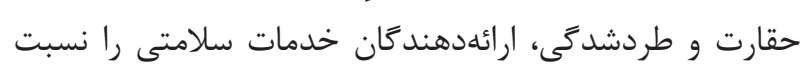

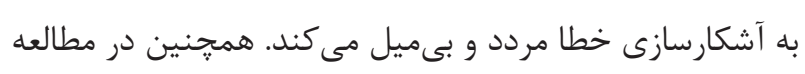

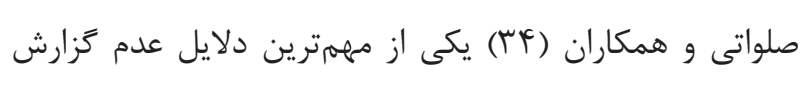
خطا تمركز مسئولين بر شخص اشتباه كننده بدون توجه ساير

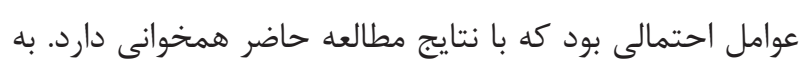

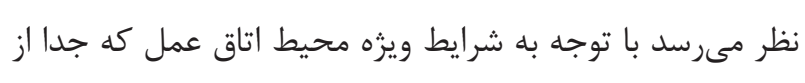

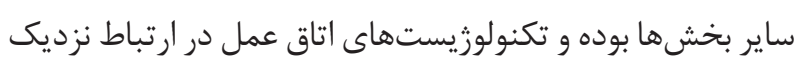

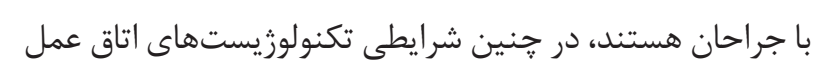

اجراى سيسته يادكيرى از خطا در جهت افزايش ايمنى بيمار حائز

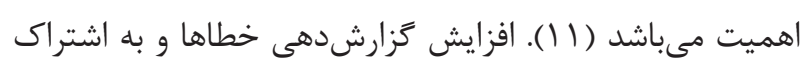

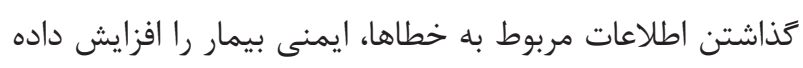
و از رخداد دوباره خطاها جلوَّيرى مى كند؛ بنابراين كاركنان

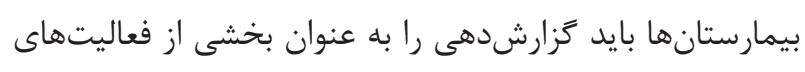

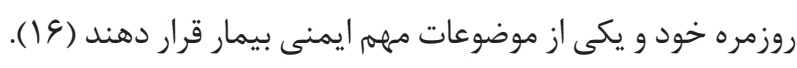

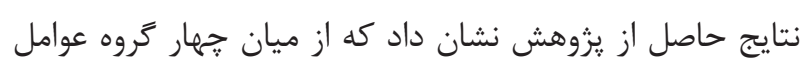
قانونى، فرهنَ سازمانى، مقررات نظارتى و عوامل مالى از ديدَّاه

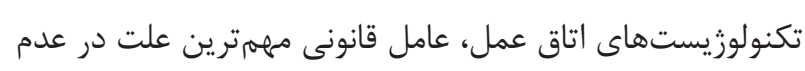

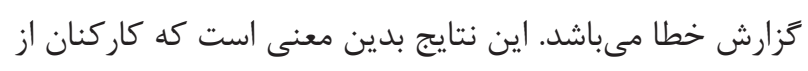

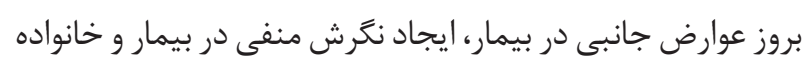

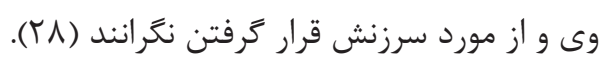

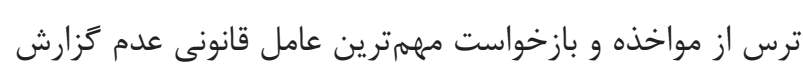
خطا مىباشد كه در اين زمينه نتايج مطالعه حاضر با نتائ بازيج

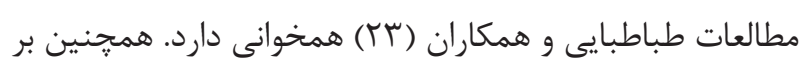
اساس يافتههاى مطالعات رضايى و همكاران بيشتر ين دلايل عدم همان

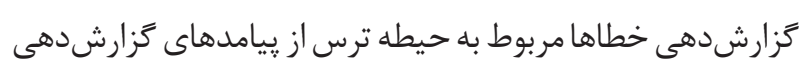

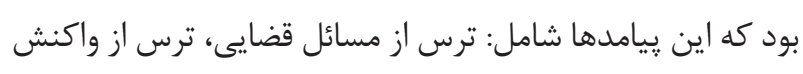

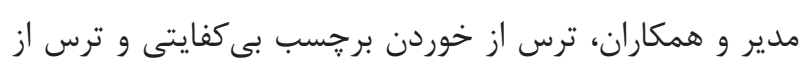

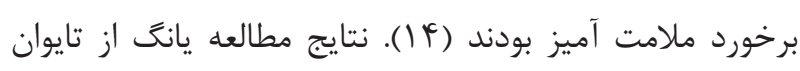

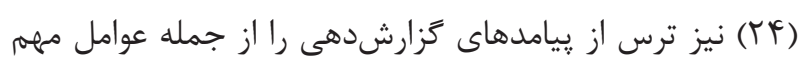
بازدارنده گزارش دهى خطا برشمردند. ترونر (Toruner) و همكاران در تركيه ترس از بروز عوارض جانبى در بيمار و از دست دادن بان بردان

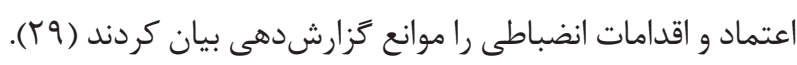
به نظر مىرسد كه برخى يرسنل به دليل فرار از تنبيه و رفتارهاى

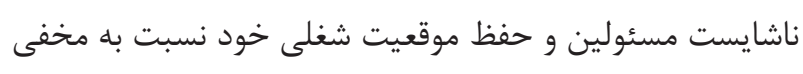
كردن و كزارش ندادن خطاى خود اقدام كنند كه لازم است

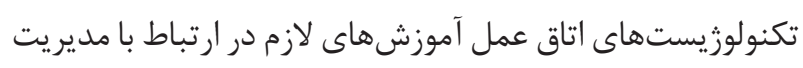

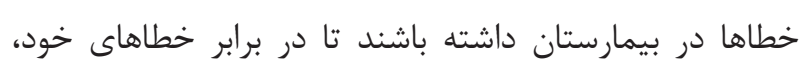
مسئوليت يذير باشند.

به طور كلى، برخوردهاى نامناسب به دنبال بروز خطاها و اشتباهات

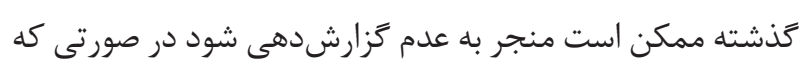

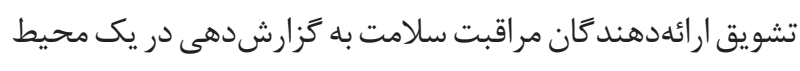
غير تنبيهى همراه با بهبود مداوم سيستم كزارشدهنى، مى تواند 
كزارشدهى خطا بود كه لازم است با توسعه كار تيمى در يرسنل،

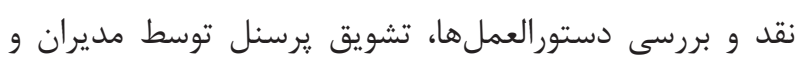

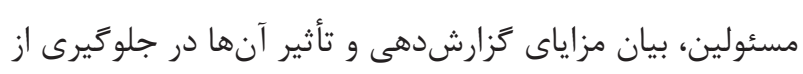

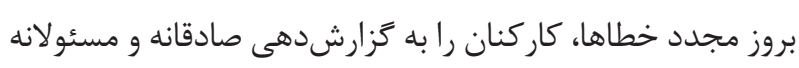

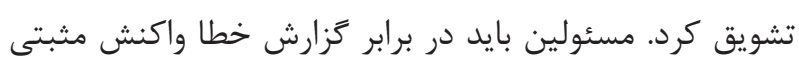

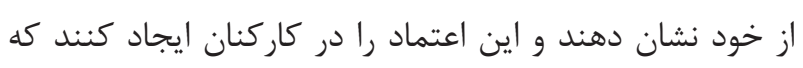

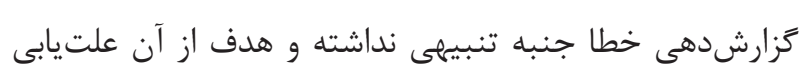

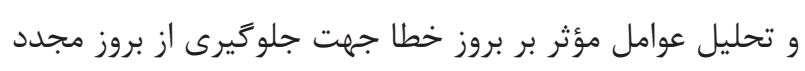
آن مىباشد. از جمله محدوديتهاى يزوهش حاضر، شناسايى موانع تزارشدهى

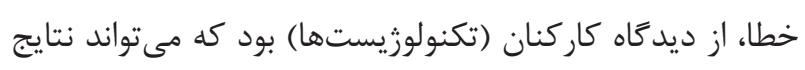

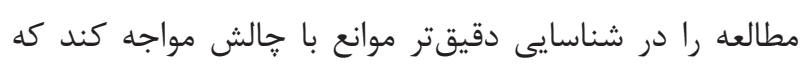
״يشنهاد مىشود به شيوه مشاهدهاى و ارزيابى فعاليت نيز انجام شود. بركزارى دورههاى آموزشى تحليل خطا، طراحى فرمها و

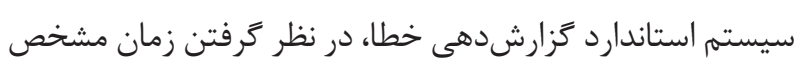
براى كزارشدهى خطا در بخش و طراحى نظام تشويق و تنبيه

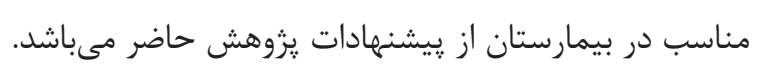

\section{تشكر و قدردانى}

اين مقاله حاصل ياياننامه كارشناسى ارشد تكنولوزى اتاق عمل كل

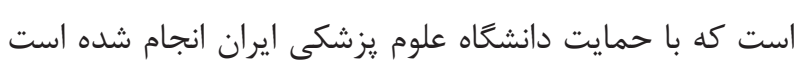

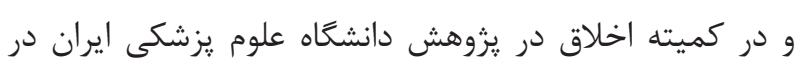

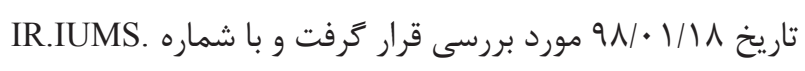

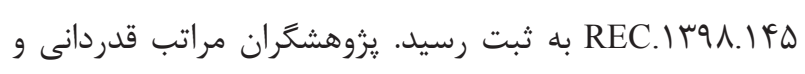

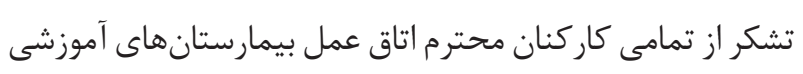
وابسته به دانشعاه علوم يزشكى ايران را اعلام مى دارند.

تضاد منافع بدينوسيله نويسندكان تصريح مى كنند كه هيجزَّنه تضاد منافعى در خصوص يزوهش حاضر وجود ندارد.
مى كنند تا ضعفى از خود بروز ندهند در صورتى كه مواخذه و

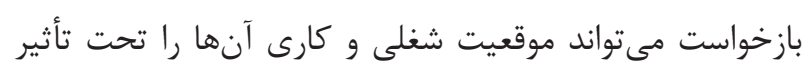
قرار دهد. آخرين حيطهاى كه مورد بررسى قرار كرفت عامل مالى بود. از دست دادن شهرت و يا شغل داراى بيشترين اهميت بود. يافتههاى مورد بردي

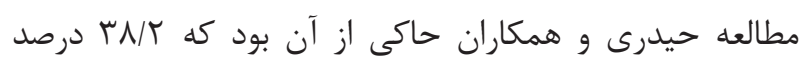

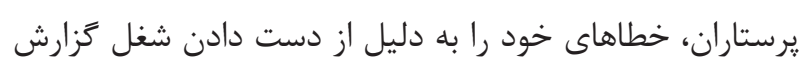

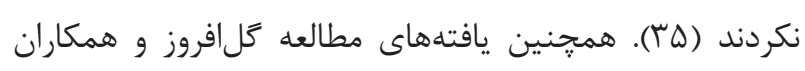

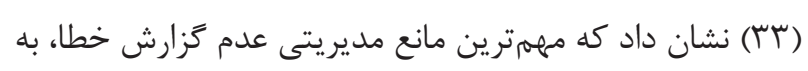

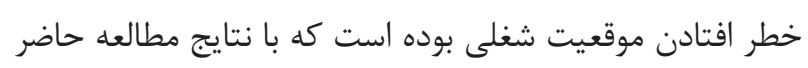

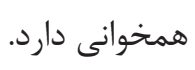
در مطالعه حاضر برخلاف اينكه تكنولوزيستهاى اتاق عمل حجم

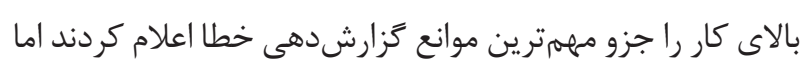

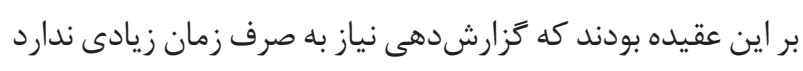

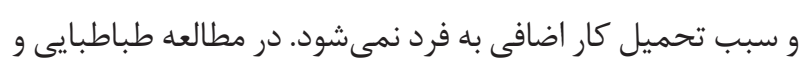

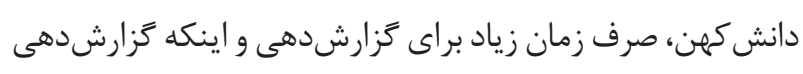

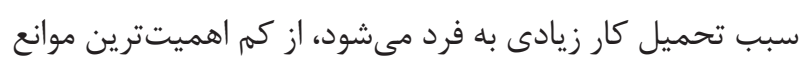

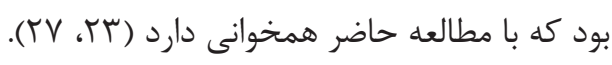

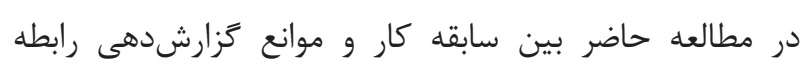

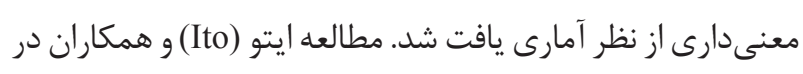

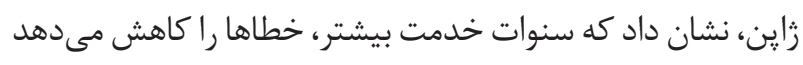

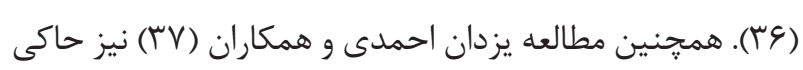
از اين بود كه سنوات خدمت بيشتر، خطاها را كاهش مى مهديد.

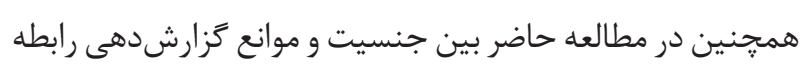
معنى دارى از نظر آمارى مشاهده شد. در مطالعه آذر آباد و همكاران

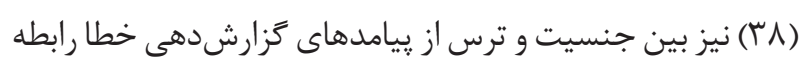

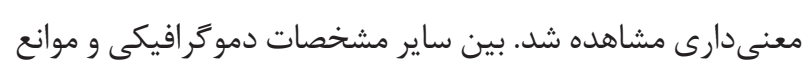

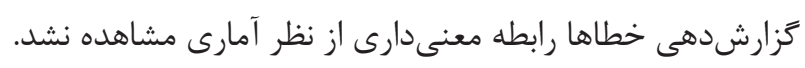

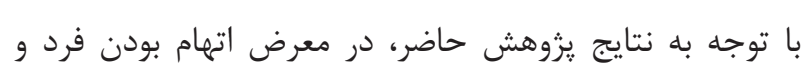

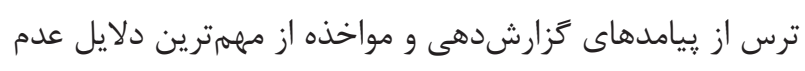




\section{References}

1- Ugur E, Kara S, Yildirim S, Akbal E. Medical errors and patient safety in the operating room. Age. 2016; 33(6.53):19-50. PMID: 27183943

2- Nabhan M, Elraiyah T, Brown DR, Dilling J, LeBlanc A, Montori $\mathrm{VM}$, et al. What is preventable harm in healthcare? A systematic review of definitions. BMC health serv res. 2012; 12(1): 128. DOI: 10.1186/1472-6963-12-128

3- Zagheri Tafreshi M, Rassouli M, Zayeri F, Pazookian M. Development of nurses' medication error model: Mixed method. Quarterly Journal of Nersing Management. 2014; 3(3): 50-3. (Persian)

4- Haynes AB, Weiser TG, Berry WR, Lipsitz SR, Breizat A-HS, Dellinger EP, et al. Changes in safety attitude and relationship to decreased postoperative morbidity and mortality following implementation of a checklist-based surgical safety intervention. BMJ quality \& safety. 2011; 20(1): 102-7. DOI: 10.1136/ bmjqs.2009.040022 PMID: 21228082

5- Abolghasem GH, Ravaghi H, Pirouzi M, Mansourzade A. Utilizing Integrated Prospective and Retrospective Risk Analysis Method on General Processes Patient Flow in Operating Room in Seyed Alshohada Hospital in Semirom, Iran. Health Information Management. 2013; 10(3): 488-97. (Persian)

6- Lewis SJ, Andersen HK, Thomas S. Early enteral nutrition within $24 \mathrm{~h}$ of intestinal surgery versus later commencement of feeding: a systematic review and meta-analysis. Journal of Gastrointestinal Surgery. 2009; 13(3): 569. DOI: 10.1007/s11605-008-0592-x PMID: 18629592

7- Weerakkody RA, Cheshire NJ, Riga C, Lear R, Hamady MS, Moorthy K, et al. Surgical technology and operating-room safety failures: A systematic review of quantitative studies. BMJ Qual Saf. 2013; 22(9): 710-8. DOI: 10.1136/bmjqs-2012-001778 PMID: 23886892

8- khammarnia $\mathrm{m}$, ravangard $\mathrm{r}$, ghanbari jahromi m, moradi a. Survey of Medical Errors in Shiraz Public Hospitals: 2013. Hospital. 2014; 13(3): 17-24. (Persian)

9- Schwappach DL, Frank O, Davis RE. A vignette study to examine health care professionals' attitudes towards patient involvement in error prevention. Journal of evaluation in clinical practice. 2013; 19(5): 840-8. DOI: 10.1111/j.1365-2753.2012.01861.x PMID: 22639922

10- farzi s, Abedi HA, Ghodousi A, Yazdannik AR. Medication Errors Experiences of Nurses who Working in Hospitals of Isfahan at 1391. Journal of qualitative Research in Health Sciences. 2014; 2(4): 310-9

11- Ontario HQ. Patient safety learning systems: A systematic review and qualitative synthesis. Ontario health technology assessment series. 2017; 17(3): 1. PMID: 28326148 PMCID: PMC5357133

12- Hoffmann B, Beyer M, Rohe J, Gensichen J, Gerlach F. "Every error counts": A web-based incident reporting and learning system for general practice. BMJ Quality \& Safety. 2008; 17(4): 307-12.
DOI: 10.1136/qshc.2006.018440 PMID: 18678731

13- Movahednia S, Partovishayan Z, Bastanitehrani M, Moradi F. Nurse Managers' perspectives about Reasons for not reporting medical errors in Firoozgar Hospital: 2012. Razi Journal of Medical Sciences. 2014; 21(125): 110-8. (Persian)

14- Musarezaie A, Momeni GGT, Zargham BA, Haj SE. Survey of the medication errors and refusal to report medication errors from the viewpoints of nurses in hospitals affiliated to Isfahan University of medical sciences, Iran. 2013; 9(1): 76-85. (Persian)

15- Pham JC, Story JL, Hicks RW, Shore AD, Morlock LL, Cheung DS, et al. National study on the frequency, types, causes, and consequences of voluntarily reported emergency department medication errors. The Journal of emergency medicine. 2011; 40(5): 485-92. DOI: 10.1016/j.jemermed.2008.02.059 PMID: 18823735

16- Louis MY, Hussain LR, Dhanraj DN, Khan BS, Jung SR, Quiles WR, et al. Improving patient safety event reporting among residents and teaching faculty. Ochsner J. 2016; 16(1): 73-80. PMID: 27046410 PMCID: PMC4795509

17- Wolf ZR, Hughes RG. Error reporting and disclosure. 2008.35. PMID: 21328753

18- Hashemi F. Ethical response to nursing error. Journal of Medical Ethics and History of Medicine. 2008; 1(4): 31-46. (Persian)

19- Shanty JA. The Influence of Perceived Safety Culture and Nurses' Work Environment on Medication Error Occurrence and Reporting: West Virginia University; 2011.

20- Anoosheh M, Ahmadi F, Faghihzadeh S, Vaismoradi M. Causes and management of nursing practice errors: a questionnaire survey of hospital nurses in Iran. Int nurs rev. 2008; 55(3): 288-95. DOI: 10.1111/j.1466-7657.2008.00623.x PMID: 19522944

21- Najafi H, editor Medication prescription error is one of the most common errors in medical professional. Proceedings of the 1 st International Congress of Forensic Medicine; 2009.

22- Hughes R. Patient safety and quality: An evidence-based handbook for nurses: Agency for Healthcare Research and Quality Rockville, MD; 2008.

23- Tabatabaee SS, Kalhor R, Nejatzadegan Z, Kohpeima Jahromi V, Sharifi T. Barriers to medication error reporting from nurses' perspective: A private hospital survey. International Journal of Hospital Research. 2014; 3(2): 97-102. (Persian)

24- Yung HP, Yu S, Chu C, Hou IC, Tang FI. Nurses' attitudes and perceived barriers to the reporting of medication administration errors. Journal of nursing management. 2016; 24(5): 580-8. DOI: 10.1111/jonm.12360 PMID: 26888342

25- Anderson B, Stumpf PG, Schulkin J. Medical error reporting, patient safety, and the physician. J patient saf. 2009; 5(3): 176-9. DOI: 10.1097/PTS.0b013e3181b320b0 PMID: 19927051

26- Aboshaiqah AE. Barriers in reporting medication administration errors as perceived by nurses in Saudi Arabia. Middle-East J Sci Res. 2013; 17(2): 130-6. DOI: 10.5829/idosi.mejsr.2013.17.02.76110 
27- Kohan AD, Mahfoozpour S, Palesh M, Ouchhesar FF. Assessing barriers to medical errors reporting among clinical staff members of teaching hospitals affiliated with Shahid Beheshti University of Medical Sciences in Tehran-2016. Journal of Health in the Field. 2018; 5(3). 8-16.

28- Wolf ZR, Hughes RG. Error reporting and disclosure. Patient safety and quality: An evidence-based handbook for nurses: Agency for Healthcare Research and Quality (US); 2008.

29- Toruner EK, Uysal G. Causes, reporting, and prevention of medication errors from a pediatric nurse perspective. Australian Journal of Advanced Nursing, The. 2012; 29(4): 28- 35.

30- Safety ACo, Care QiH. National safety and quality health service standards: Australian Commission on Safety and Quality in Health Care; 2012.

31- Haw C, Stubbs J, Dickens GL. Barriers to the reporting of medication administration errors and near misses: An interview study of nurses at a psychiatric hospital. J Psychiatr Ment Health Nurs. 2014; 21(9): 797-805. DOI: 10.1111/jpm.12143 PMID: 24646372

32- Elder NC, Graham D, Brandt E, Hickner J. Barriers and motivators for making error reports from family medicine offices: A report from the American Academy of Family Physicians National Research Network (AAFP NRN). J Am Board Fam Med. 2007; 20(2):115-23. DOI: $10.3122 / \mathrm{jabfm} .2007 .02 .060081$

\section{PMID: 17341747}

33- Golafrooz M, Sadeghi H, Ghaedi F, Tabarraei Y, Keighobadi F, Keighobadi F. Managerial and moral obstacles in reporting nursing errors: nurses' view point. Journal of Medical Ethics \& History of Medicine. 2014; 7(1): 65-76. (Persian)

34- Salavati S, Hatamvand F, Tabesh H. Nurses' Perspectives on Causes of Medication Errors and Non-Reporting at ED. Iran journal of nursing. 2012; 25(79): 72-83. (Persian)

35- Heydari H, Kamran A, Pirzadeh A. Assessment of Nurses'Perceived Barriers and Behaviors to Reporting Medication Errors in Hospitals of Lorestan University of Medical Sciences, Iran. 2012; 8(5): 806-13. (Persian)

36- Ito H, Yamazumi S. Common types of medication errors on longterm psychiatric care units. International Journal for quality in health care. 2003; 15(3): 207-12. DOI: 10.1093/intqhe/mzg038

37- Ahmadi Y, Pishgooie SAH, Sepandi M, Beheshtifar M, Doosi H. Organizational Factors Affecting on making of Drug Errors from the Viewpoint of Nursing Personnel Employed in Selected Military Hospitals in Tehran. Military Care Sciences.2018; 5 (2). 104-111. DOI: 10.29252/mcs.5.2.104 (Persian)

38- Azarabad S, Zaman SS, Nouri B, Valiee S. Frequency, Causes and Reporting Barriers of Nursing Errors in the Operating Room Students. Research in Medical Education. 2018; 10(2):18-27. DOI: $10.29252 /$ rme.10.2.18 